\title{
Acquisition and Classification System of EMG Signals for Interpreting the Alphabet of the Sign Language
}

\author{
Alvarado-Diaz Witman ${ }^{1}$, Meneses-Claudio Brian ${ }^{2}$, Fiorella Flores-Medina ${ }^{3}$ \\ Patricia Condori ${ }^{4}$, Natalia I. Vargas-Cuentas ${ }^{5}$, Avid Roman-Gonzalez ${ }^{6}$ \\ Image Processing Research Laboratory (INTI-Lab) \\ Universidad de Ciencias y Humanidades, Lima, Peru
}

\begin{abstract}
Taking into account that in Peru, there is an increase in people with difficulties in speaking or communicating. According to the National Institute of Statistics and Informatics of Peru (INEI for its acronym in Spanish), around 80000 people use the gesturing language. For this reason, this research proposes to use the electromyography (EMG) signals to detect the hand movement and identify the alphabet of the sign language to provide essential communication to people who need it. The idea is to classify the signals and recognize the letters of the Spanish alphabet, interpreted in the Peruvian sign language. The results show the classification of the 27 letters of the alphabet with a general success rate of $93.9 \%$.
\end{abstract}

Keywords-Electromyography; EMG; sign language; essential communication; recognize the letters

\section{INTRODUCTION}

In the national report of the sociodemographic profile [1], carried out by the National Institute of Statistics and Informatics (INEI for its acronym in Spanish), it mentions that in Peru $10.4 \%$ of the population suffers from a disability, of which $3.1 \%$ have difficulty to speak or communicate. Based on this problem, the present work proposes the use of electroencephalography (EMG) signals in order to provide essential communication for people with difficulties to speak, for this purpose the classification of the signals, produced in the muscles is performed by performing gestures that denote the letters of the alphabet.

The Ministry of Education of Perú, through the General Direction of the Basic Special Education (DIGEBE for its acronym in Spanish) makes available the document "Peruvian Sign Language" [2], in which it is mentioned that sign language is a communication system which is perceived through sight and requires the use of the hands as active articulators, the use of space as a place of articulation (phonological structure) and as a temporary reference.

To obtain data, the Myoware system was used as a basis [3] which is an electronic system to obtain the electrical activity produced by the muscles, they are commonly used in prostheses, robotics and much more; the Myoware detects the electrical activity of the muscles, and then convert it into a variable voltage that can be read in the analog input pin of any microcontroller, in our case, it will use the Arduino UNO board.
In [4] the use of the electromyogram (EMG) data provided by the Myo bracelet is evaluated as characteristics for the classification of 20 stationary letter gestures of the Brazilian Sign Language alphabet. The classification was done using Support Vector Machines (SVM). The results obtained show that it is possible to identify the gestures.

In [5], they present an interface to capture facial muscle data. This system is based on the recognition of syllables of the Spanish language. The signals of each articulated syllable (with silent voice) were transformed into a vector of characteristics that are used to train a classification algorithm. Experimental results demonstrated effectiveness in three subjects, providing an average classification rate of almost $70 \%$ for 30 classes.

In [6] a TDM (Time derivative moments) feature set extraction is proposed to improve the performance of EMGPR (Electromyography Pattern Recognition) in the classification of upper limb movement. They use a standard database to examine the proposed feature set. Finally, 97.6\% of effectiveness was obtained in the classification of 8 different kinds of movements.

In [7] an American sign language recognition system is proposed using Electromyography; its objective was to recognize the letters of the sign language alphabet and allow users to spell words and sentences. The signals were acquired from the right forearm for 27 gestures. Methods extraction such as Time domain, frequency domain (band power), power spectral density (band power), and average power features were used. Also, as a classification method, Support Vector Machine (SVM) and Ensemble Learning algorithm were used; obtaining a percentage of effectiveness of $80 \%$.

The main objective of this research is to provide a basic communication between people who use sign language to communicate, this document presents the primary results obtained; which demonstrate the possibility of using our methodology as a system to interpret sign language, it works continue

Section II presents the methodology that has been followed for the research work. In Section III are the preliminary results obtained, and finally, in Sections IV and V are the respective discussions and conclusions. 


\section{Methodology}

there are different methodologies for interpreting sign language, however the methodology presented below is used due to the ease which the data can be obtained, and because of the experience in the treatment of data. themselves; Finally, in conclusión is an agile and practical methodology.

For the present research work, the methodology to follow is schematized in the block diagram shown in Fig. 1.

\section{A. Data Acquisition}

For the data acquisition, the system described in [2] in which the Myoware device is used will be used, this device will be connected to an Arduino Uno board, which will acquire the signals and send them by serial port of the computer. In Fig. 2, one can see the mentioned system, in addition to the acquired signals, by representing with the left hand a random position to check the operation of the system.

A graphical interface is created in Matlab (Fig. 3), in which data will be taken, in addition to performing the signal processing, which will be explained in the next section. The data is saved in files with extension ".mat", which is an extension of Matlab; these files contain the data corresponding to the four channels that the system has.

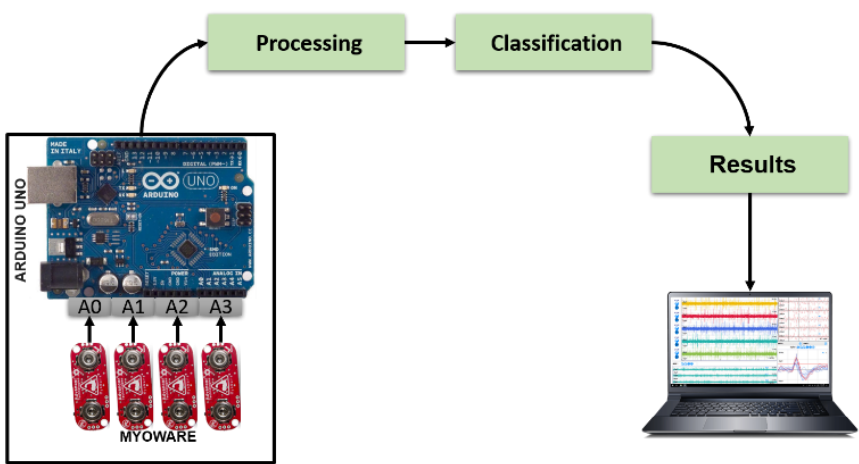

DATAACQUISITION

Fig. 1. Block Diagram of the Methodology.

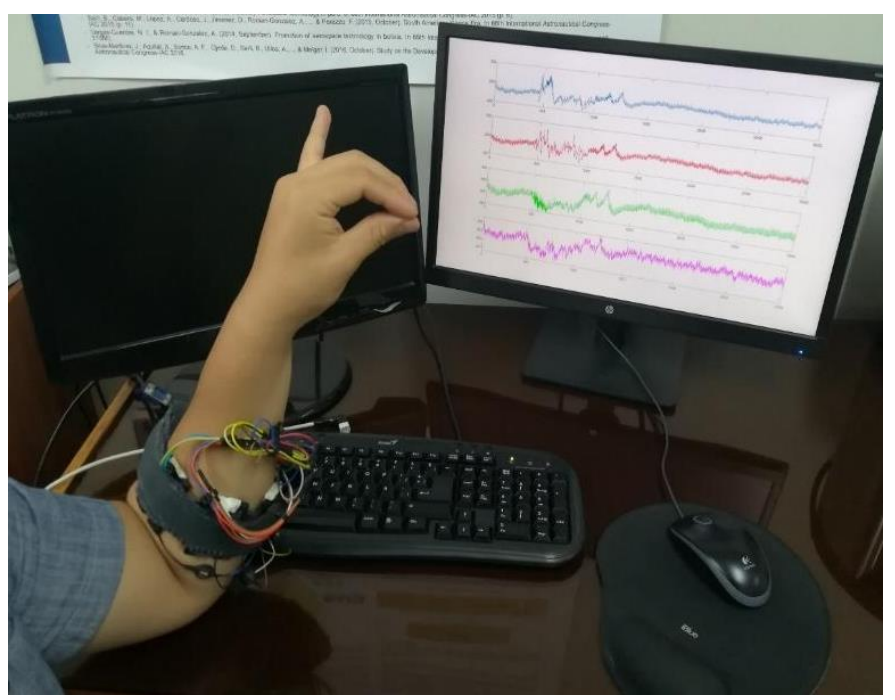

Fig. 2. Data Acquisition.

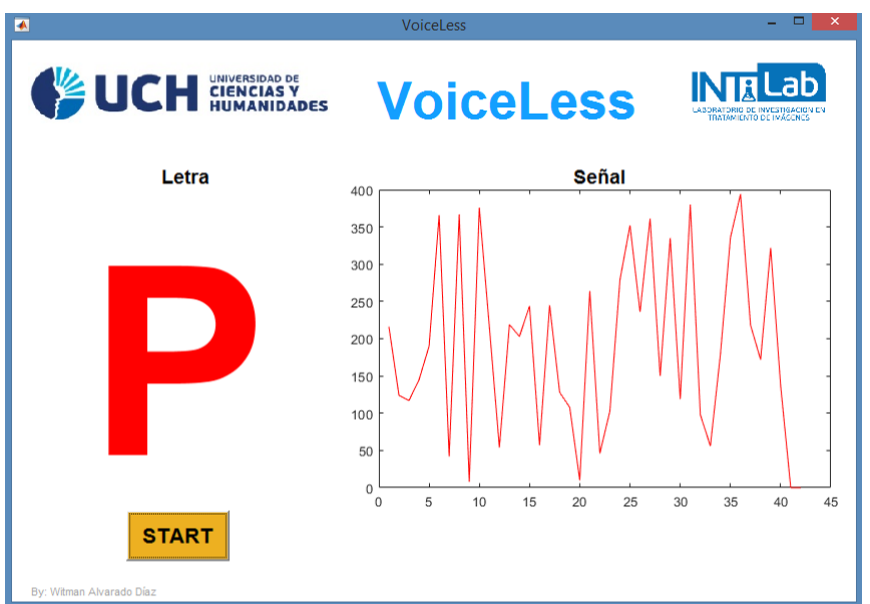

Fig. 3. VoiceLess Graphic Interface.

\section{B. Processing and Classification}

For the processing and classification stage, the algorithm of Fig. 4 is used. The classification stage is already included, in the external function, in addition to a prediction stage.

The diagram of the external function can be seen in Fig. 5, it can observe the stage of characteristics extraction, which consists of 8 characteristics of which 4 are from the domain of frequency and the other 4 in the domain of time, the proposed characteristics are: The maximum value, average data, variance, and standard deviation; then these characteristics are grouped and classified as well used to predict the letter made through sign language.

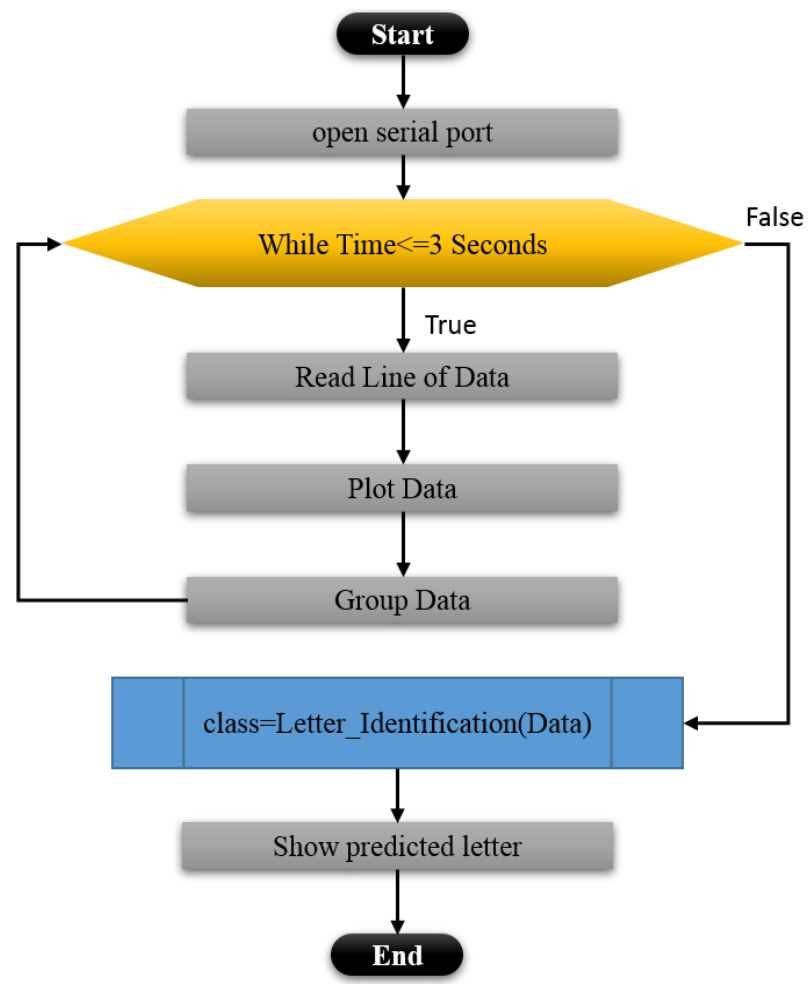

Fig. 4. Flow Diagram of the VoiceLess Graphical Interface. 


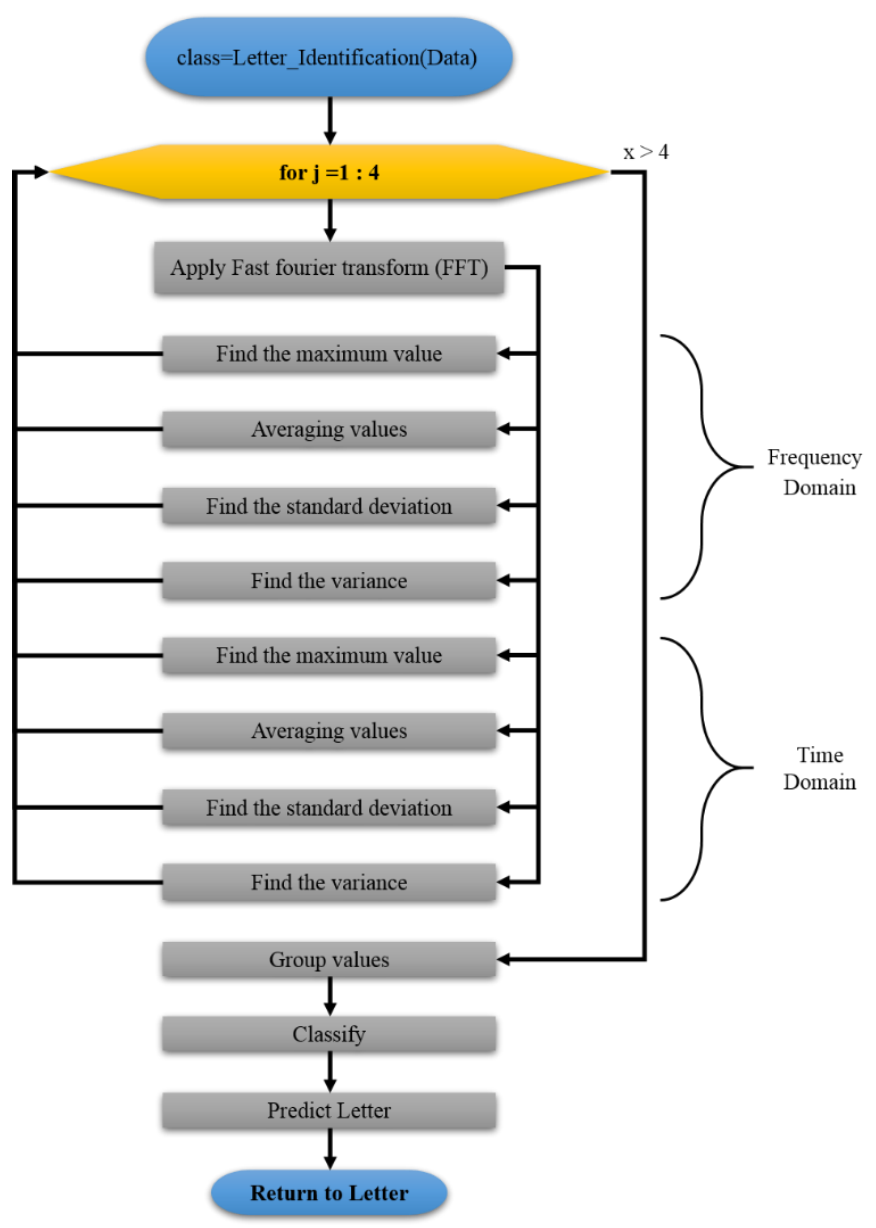

Fig. 5. Scheme of Data Processing.

It has to take in mind that it will work with signals with an amplitude between 0 to $10 \mathrm{mV}$ and a frequency of 10 to $100 \mathrm{~Hz}$ [8], [9], [10] and [11], [2], and that each data channel is extracted, then finding the fast Fourier transform; next, the above-mentioned characteristics are calculated.

\section{RESUltS}

Taking in mind that it will first analyze the data that was taken from the left forearm, with the methodology proposed in [2]; Sampling is done as follows: the first 3 seconds no movement is made, the 3 seconds after the representation of a letter of the Peruvian Sign Alphabet is performed, finally in the last 3 seconds no movement is made; It is worth mentioning that samples are taken from a healthy person. Five samples are taken for each of the 27 letters of the alphabet.

In Fig. 6(a), it can see the signals obtained from the representation of the letter " $\mathrm{H}$ ", corresponding to channels 1,2,3 and 4; in Fig. 6(b), it can see some of the characteristics obtained from the fourth channel; it can see that there are apparent differences between one and other signals.

The characteristics obtained from all the data were introduced in the Classification Learner application, which can be seen in Fig. 7, which shows the graph of the characteristics of the 27 categories entered.

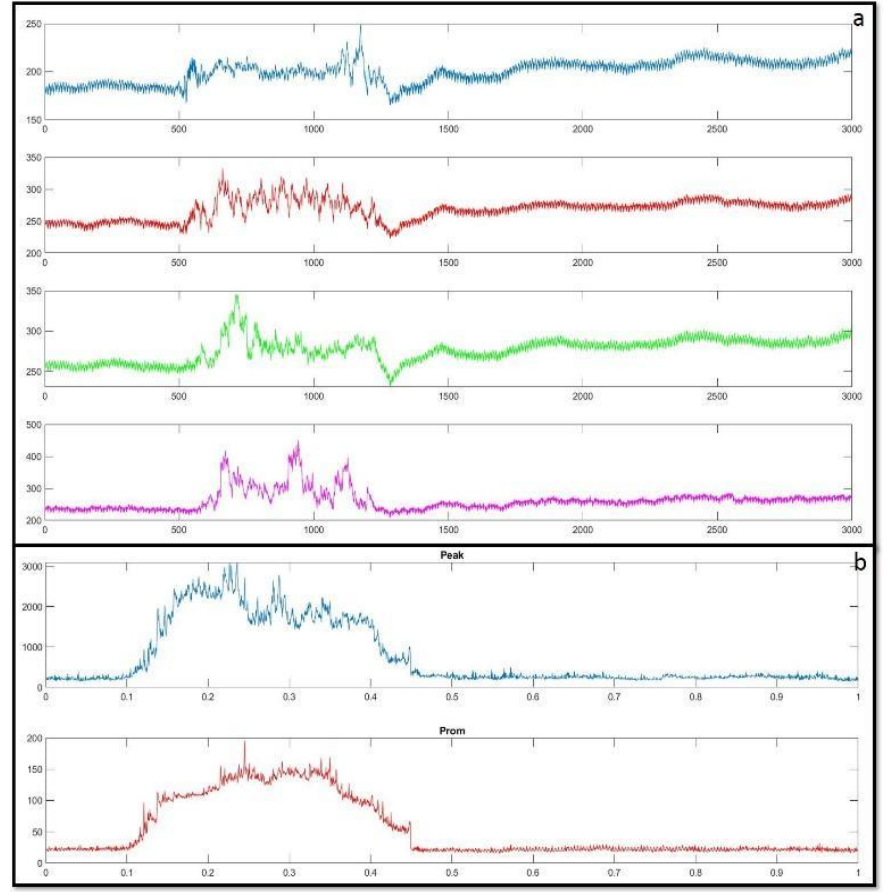

Fig. 6. Raw Signals in Each Data Channel. (b) Graph of the Characteristics of the Data on Channel 4.

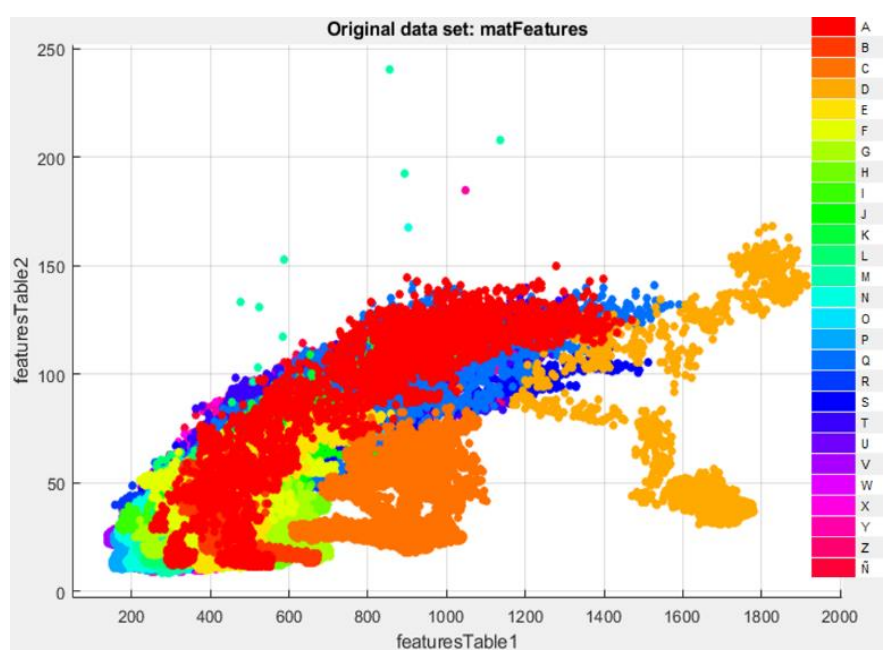

Fig. 7. Characteristics Plotted in the Classification Learner Application.

The same application generates a general rate of some 93.9\% and also provides with the necessary data for the construction of a confusion matrix, from which the results shown in Table I are extracted.

From this table, it randomly choose 4 letters "A", "P", "U" and " $\mathrm{Z}$ " and submit it to the algorithms described in the methodology section, in order to check if the predictions of the letters are made correctly, for which, with the graphical interface, 32 repetitions of each chosen letter are taken, with which the results of Table II were obtained.

As we can see in Table II, ten repetitions were made to the letter "P" was the most successful, followed by the letter "A", "U" and finally "Z". 
TABLE. I. TABLE OF ACCURACY

\begin{tabular}{|c|c|c|c|c|}
\hline \multirow[b]{2}{*}{ Class } & \multicolumn{2}{|c|}{ True class } & \multicolumn{2}{|c|}{ Predicted class } \\
\hline & $\begin{array}{l}\text { True } \\
\text { Positive } \\
\text { Rate }\end{array}$ & $\begin{array}{l}\text { False } \\
\text { Negative } \\
\text { Rate }\end{array}$ & $\begin{array}{l}\text { Positive } \\
\text { Predictive } \\
\text { Value }\end{array}$ & $\begin{array}{l}\text { False } \\
\text { Discovery } \\
\text { Rate }\end{array}$ \\
\hline $\mathbf{A}$ & $98.8 \%$ & $1.2 \%$ & $98.5 \%$ & $1.5 \%$ \\
\hline B & $99.5 \%$ & $0.5 \%$ & $99.6 \%$ & $0.4 \%$ \\
\hline $\mathbf{C}$ & $100.0 \%$ & $0 \%$ & $100.0 \%$ & $0 \%$ \\
\hline D & $100.0 \%$ & $0 \%$ & $100.0 \%$ & $0 \%$ \\
\hline $\mathbf{E}$ & $98.8 \%$ & $1.2 \%$ & $99.1 \%$ & $0.9 \%$ \\
\hline $\mathbf{F}$ & $97.5 \%$ & $2.5 \%$ & $96.8 \%$ & $3.2 \%$ \\
\hline G & $96.7 \%$ & $3.3 \%$ & $98.1 \%$ & $1.9 \%$ \\
\hline $\mathbf{H}$ & $97.8 \%$ & $2.2 \%$ & $97.9 \%$ & $2.1 \%$ \\
\hline I & $98.9 \%$ & $1.1 \%$ & $98.7 \%$ & $1.3 \%$ \\
\hline $\mathbf{J}$ & $99.8 \%$ & $0.2 \%$ & $97.6 \%$ & $2.4 \%$ \\
\hline $\mathbf{K}$ & $99.6 \%$ & $0.4 \%$ & $99.3 \%$ & $0.7 \%$ \\
\hline $\mathbf{L}$ & $91.7 \%$ & $8.3 \%$ & $94.3 \%$ & $5.7 \%$ \\
\hline $\mathbf{M}$ & $97.9 \%$ & $2.1 \%$ & $97.3 \%$ & $2.7 \%$ \\
\hline $\mathbf{N}$ & $93.3 \%$ & $6.7 \%$ & $94.5 \%$ & $5.5 \%$ \\
\hline $\mathbf{O}$ & $96.9 \%$ & $3.1 \%$ & $96.3 \%$ & $3.7 \%$ \\
\hline $\mathbf{P}$ & $96.8 \%$ & $3.2 \%$ & $97.5 \%$ & $2.5 \%$ \\
\hline $\mathbf{Q}$ & $91.8 \%$ & $8.2 \%$ & $90.4 \%$ & $9.6 \%$ \\
\hline $\mathbf{R}$ & $85.8 \%$ & $14.2 \%$ & $86.4 \%$ & $13.6 \%$ \\
\hline $\mathbf{S}$ & $87.6 \%$ & $12.4 \%$ & $88.9 \%$ & $11.1 \%$ \\
\hline$T$ & $88.8 \%$ & $11.2 \%$ & $89.7 \%$ & $10.3 \%$ \\
\hline $\mathbf{U}$ & $83.0 \%$ & $17.0 \%$ & $89.0 \%$ & $11.0 \%$ \\
\hline $\mathbf{V}$ & $91.5 \%$ & $8.5 \%$ & $89.5 \%$ & $10.5 \%$ \\
\hline $\mathbf{W}$ & $88.1 \%$ & $11.9 \%$ & $90.5 \%$ & $9.5 \%$ \\
\hline $\mathbf{X}$ & $93.4 \%$ & $6.6 \%$ & $92.6 \%$ & $7.4 \%$ \\
\hline $\mathbf{Y}$ & $90.5 \%$ & $9.5 \%$ & $90.3 \%$ & $9.7 \%$ \\
\hline $\mathbf{Z}$ & $94.1 \%$ & $5.9 \%$ & $90.2 \%$ & $9.8 \%$ \\
\hline$\overline{\tilde{\mathbf{N}}}$ & $89.0 \%$ & $11.0 \%$ & $92.4 \%$ & $7.6 \%$ \\
\hline
\end{tabular}

TABLE. II. PREDICTED ACCURACY

\begin{tabular}{|l|l|l|}
\hline WORDS & TRUE & FALSE \\
\hline A & 7 & 3 \\
\hline $\mathbf{P}$ & 9 & 1 \\
\hline $\mathbf{U}$ & 6 & 4 \\
\hline $\mathbf{Z}$ & 5 & 5 \\
\hline
\end{tabular}

\section{Discussion AND CONCLUSIONS}

In [4] for the classification of 20 stationary letter gestures of the Brazilian sign language alphabet, a minimum efficiency of $96.01 \%$ was obtained. In the consultation [5], in recognition of Spanish language syllables provides an average classification rate of almost $70 \%$ for 30 classes. In the consultation [6] in the classification of the movement of the upper limb through various gestures, $97.6 \%$ effectiveness is obtained in the classification of 8 classes. In the consultation [7] in recognition of the letters of the American sign language alphabet, an $80 \%$ effectiveness was obtained. In none of the research works consulted was the test carried out if the proposed classifier correctly predicts the letters of the alphabet.

In conclusion, the classification of EMG signals has been achieved. On this research paper, using 4 data channels have reached an overall percentage of correct answers of $93.9 \%$ so, to improve the rate of predictions and repeatability of our system, it is necessary to add more samples until a moderate prediction is achieved. As a future work, it is proposed to make 128 samples per letter in addition to improving the hardware and communication with the $\mathrm{PC}$, in order to have a higher sampling frequency of signals, which will show more accurate data of the movements made with hand, it is expected to achieve the objective of VoiceLess, t's to provide essential communication to people are deficient so to communicate.

\section{REFERENCES}

[1] INEI, "Perfil Sociodemográfico, Informe Nacional," 2018.

[2] A.-D. Witman, M.-C. Brian, and R.-G. Avid, "Electromyography Signal Acquisition and Analysis System for Finger Movement Classification," 2019.

[3] K. Hartman, "Getting Started with MyoWare Muscle Sensor," 2018.

[4] J. G. Abreu, J. M. Teixeira, L. S. Figueiredo, and V. Teichrieb, "Evaluating Sign Language Recognition Using the Myo Armband," Proc.-18th Symp. Virtual Augment. Reality, SVR 2016, pp. 64-70, 2016.

[5] E. Lopez-Larraz, O. Mozos, J. Antelis, and J. Minguez, "Syllable-based speech recognition using auditorylike features," 32nd Annu. Int. Conf. IEEE EMBS, 2010.

[6] S. Pancholi and A. M. Joshi, "Time Derivative Moments Based Feature Extraction Approach for Recognition of Upper Limb Motions Using EMG," IEEE Sensors Lett., vol. PP, no. 3, pp. 1-1, 2019.

[7] C. Savur and F. Sahin, "American Sign Language Recognition system by using surface EMG signal," 2016 IEEE Int. Conf. Syst. Man, Cybern. SMC 2016 - Conf. Proc., pp. 2872-2877, 2017.

[8] S. Pancholi and R. Agarwal, "Development of low cost EMG data acquisition system for arm activities recognition," 2016 Int. Conf. Adv. Comput. Commun. Informatics, ICACCI 2016, pp. 2465-2469, 2016.

[9] R. Zhou, Q. Luo, X. Feng, and C. Li, "Design of a wireless multichannel surface EMG signal acquisition system," 2017 3rd IEEE Int. Conf. Comput. Commun. ICCC 2017, vol. 2018-Janua, pp. 279-283, 2018.

[10] M. Tariquzzaman, F. Khanam, M. H. A. Sohag, and M. Ahmad, "Design and implementation of a low cost multichannel rectified EMG acquisition system," 19th Int. Conf. Comput. Inf. Technol. ICCIT 2016, pp. 261-265, 2017.

[11] H. Ghapanchizadeh, S. A. Ahmad, and A. J. Ishak, "Developing multichannel surface EMG acquisition system by using instrument opamp INA2141,” pp. 258-263, 2014. 